\title{
ReVista Digital DE DiREITo AdMinistrativo
}

\author{
FACULDADE DE Direito de RibeirÃo PRETO
}

UNIVERSIDADE DE SÃo PAULO

\section{Seção: Artigos Científicos}

\section{Direito das águas: sujeição e emancipação}

Water rights: subjulgation and emancipation

\section{Márcio Henrique Pereira Ponzilacqua}

\begin{abstract}
Resumo: A ideia que orienta esse artigo é a reflexão sobre a sujeição ou emancipação presente no âmbito do direito e da governança das águas. 0 método principal de análise é dedutivo. Com isso, pretende-se uma abordagem que contemple o âmbito internacional até atingir as políticas públicas estaduais e municipais. Evidencia-se a legislação concernente às águas subterrâneas, especialmente aquelas respeitantes aos aquíferos.
\end{abstract}

Palavras-chave: Direito das Águas, Política Pública, Sociologia do Direito.

\begin{abstract}
The idea that guides this article is a reflection on the subjugation or emancipation under the Water Rights and its governance. The main method of analysis is deductive. Thus, the intention is an approach the intention is an approach that contemplates from the international level until it reaches the states and municipal public policies. The aim is to highlight the legislation concerning ground water, especially relating to aquifers.
\end{abstract}

Keywords: Water Rights, Policies, Sociology of Law

Disponível no URL: $\underline{w w w . r e v i s t a s . u s p . b r / r d d a}$

DOI: http://dx.doi.org/10.11606/issn.2319-0558.v3n3p658-673 


\title{
DIREITO DAS ÁGUAS: SUJEIÇÃO E EMANCIPAÇÃO
}

\author{
Marcio Henrique Pereira PONZILACQUA*
}

\begin{abstract}
Sumário: 1 Introdução; 2 Panorama geral das competências e estratégias do direito das águas; 3 Os embates em torno da apropriação simbólica e material das águas; 40 Direito das Águas e as políticas nacionais e estaduais: expressão metajurídica e emancipatória?; 5 Conclusão: o percurso legislativo e judiciário entre os embates do dizer e do fazer o direito; 6 Referências bibliográficas.
\end{abstract}

\section{Introdução}

Há discussões doutrinárias e metajurídicas, acerca da locução "recursos hídricos". É entendida por muitos autores com forte conotação econômica e utilitarista, razão pela qual acabamos por adotar, como o faz o "Código das águas", a locução "direito das águas". Mas ainda aqui no sentido genérico, a incorporar 1. o direito da água - entendida a própria subjetividade do entes naturais; 2. o direito à água, agora concentrada nos seres que necessitam da água para sua subsistência, todos os vivos (fauna, flora em sua múltipla diversidade), com ênfase para as sociedades humanas, e 3. o direito de águas como um todo, mas que respeita ao direito que protege, controla, organiza a relação humana com o líquido a que se denomina 'água', independente do aproveitamento ou não das fontes hidrológicas e de sua origem, fluviais, pluviais ou marítima. Por outro lado, até a própria configuração de recurso hídrico é inserida como espécie no campo do direito de águas, a significar o aproveito útil ou econômico das águas ${ }^{1}$.

Por certo que o Estado não outorga os direitos humanos, ele apenas os declara porque intrínsecos à própria condição existencial humana. As visões segmentadas dos direitos humanos, em gerações distintas e separadas, não favoreceram uma perspectiva integrada destes direitos. A ótica socioambiental é fundamental para a hodierna concepção dos direitos humanos e isto implica numa aprimorada consideração da dimensão educativa. É o que se depreende claramente da Declaração de Estocolmo de 1972. Todavia, embora concebidos como irrevogáveis, inalienáveis e imprescritíveis, os direitos humanos não gozam de um estatuto universal inquestionável e irrefutável. Os elementos culturais intervêm na dinâmica da consolidação jurídica e sua consideração é cogente para a precisão nocional dos direitos humanos e das políticas públicas consequentes. Por outro lado, para além de uma eficácia jurídica, restrita ao âmbito jurídico, espera-se a eficácia social da aplicação dos direitos, como medicação concreta e adequada para a emancipação social nas esferas econômico-político-social. Assim se pode lograr incisão na órbita socioambiental, com efetiva proteção do patrimônio natural e da qualidade de vida dos grupos autóctones. É, sem dúvida, um desafio enorme em se considerando o estágio atual das relações internacionais de destruição ambiental e hipossuficiência dos Estados-nações ante os desafios socioambientais. Nessa perspectiva, é relevante conceber também o quadro normativo sob esse fluxo dialético: ou seja, as normas locais, nacionais e internacionais relacionam-se na dupla dinâmica da complementaridade e da repulsão, da atração e das antinomias. É isso a que nos propomos na abordagem que segue.

\section{Panorama geral das competências e estratégias do direito das águas}

O Acordo Internacional sobre o Aquífero Guarani (AIAG), havido em San Juan (Argentina) em 02 de agosto de 2010, explicita, logo de início, as referências do direito internacional que o sustenta

\footnotetext{
* Professor Doutor da Faculdade de Direito de Ribeirão Preto da Universidade de São Paulo.

${ }^{1}$ Sobre a pertinência e a preferência da expressão "direito das águas" cf. POMPEU, 2009b, p. 47.
} 
(REPÚBLICA ARGENTINA..., 2012). Merecem destaque, por sua proximidade ao tema, as duas Resoluções da Assembleia Geral da ONU; a Resolução n. 1803 (XVIII) sobre a Soberania Permanente sobre os Recursos Naturais e a Resolução n. 63/124, sobre o Direito dos Aquíferos Transfronteiriços, além da declaração pioneira de Estocolmo de 1972, que se constitui um marco no âmbito dos direito socioambientais (Declaração da Conferência das Nações Unidas sobre Meio Ambiente Humano), e mesmo a Declaração do Rio de Janeiro sobre Meio Ambiente e Desenvolvimento, de 1992. Foram ainda referidas as da Cúpula sobre Desenvolvimento Sustentável nas Américas, de Santa Cruz de la Sierra, 1996, e as conclusões da Cúpula Mundial sobre Desenvolvimento Sustentável de Johanesburgo, 2002, Tratado da Bacia do Prata, firmado em Brasília, 1969, Acordo-Quadro sobre Meio Ambiente do MERCOSUL, firmado em Assunção, 2001 (CONFERÊNCIA..., 2012a; 2012b; CÚPULA MUNDIAL, 2012; CÚPULA DAS AMÉRICAS, 2012; VILLAR, 2012, MERCOSUL, 2001).

A vasta citação inicial ao direito ambiental internacional tem um escopo bem claro, em linhas bastante distintas, a saber: 1 . Definir a soberania e os direitos sobre o Aquífero Guarani que passara a ser tutelado por esse Acordo Internacional; 2. Explicitar a relação entre o direito ambiental e as condições de desenvolvimento integral do ser humano, conforme referidos nos vinte e seis princípios da Declaração de Estocolmo, depois ratificados e ampliados nos vinte e sete princípios da Declaração do Rio de Janeiro; 3. Evidenciar a circunscrição de cooperação político-geográfica sobre um dos mais importantes Aquíferos do mundo, que se concentra na área compreendida pelo MERCOSUL, especialmente os países pactuantes (as Repúblicas Argentina, Federativa do Brasil, do Paraguai e Oriental do Uruguai). Em outras palavras, a preocupação e as disputas crescentes sobre o patrimônio natural, notadamente os recursos hídricos, leva os países acordantes, em agosto de 2010, a essa tratativa internacional sobre Aquífero Guarani. Recordese que o Acordo Internacional é relativamente recente, constitui-se de poucos artigos (vinte e dois no total), haja vista sua perspectiva genérica e abrangente, mas com o escopo bastante claro de traduzir em ações cooperativas e estratégias pontuais de proteção. Ainda assim, temos quase o triplo de artigos do Tratado da Bacia do Prata, com apenas oito artigos em cujo texto já figuravam os propósitos de aproximação e cooperação internacional, além da "utilização racional do recurso água, especialmente através da regularização dos cursos d'água e seu aproveitamento múltiplo e equitativo" (art. 1o, b) (BRASIL, 1970).

Note-se, todavia, que em 1969, a conjuntura ainda era desenvolvimentista, e os propósitos eram indisfarçadamente economicistas, como revelam às expressões "recurso água" (art. 1oㅡ, b), "promoção e estabelecimento de indústrias de interesse para o desenvolvimento da Bacia" (art. 1o, e), "fomento da vida animal e vegetal" (art. 1o, c), que permite, inclusive, à interpretação de que esse fomento pode ser nas formas da pecuária e agricultura e, o mais explícito, que é o art. 1ํ, f: complementação econômica de áreas limítrofes (BRASIL, 1970). 0 Tratado de 1969 tem conteúdo e contextos bastante diversos daquele da Cúpula das Américas de Santa Cruz de la Sierra, acontecida em 07 e 08 de dezembro de 1996. A proximidade com a Conferência do Rio (ECO-92), fez com que a Declaração de Santa Cruz se constituísse como um marco na explicitação dos princípios socioambientais. Em termos de estrutura, também ela se apresenta enxuta em número de partes (dez no total): a primeira parte consiste num registro das partes acordantes e dos precedentes internacionais que a ensejaram; as nove restantes ao modo de princípios apresentam-se com maior desenvolvimento redacional do que as declarações congêneres sobre meio ambiente. Valorizam-se a biodiversidade presente nas Américas e a sua rica tradição político-cultural, a preservação do meio ambiente sadio, a necessidade de integração e a complexidade dos assuntos ambientais é explicitada. Ao mesmo tempo, sente a necessidade do alívio da pobreza que deve ser pensada como parte integrada do desenvolvimento sustentável. Reconhece a questão ambiental como basilar ("pedra angular") da cooperação entre os estados americanos, como citado na penúltima parte ou 
tópico, de n. 9. Ressalte, por exemplo, a ideia da dimensão social da questão ambiental, presente no tópico seguinte, de n. 10, com o fim explícito de superação da "pobreza e marginalidade", suas conexões com a segurança alimentar e com a saúde, especialmente de grupos vulneráveis, muitos deles citados no corpo do Acordo (mulheres, crianças, indígenas, quilombolas, outras comunidades tradicionais). Junto disso, há o propósito declarado de "fortalecimento das estruturas jurídicas", em busca de avanços no âmbito do Direito Internacional Ambiental, bem como de participação pública associada ao princípio de crescimento econômico com equidade, aliado a medidas de desenvolvimento e transferência de tecnologia (CÚPULA DAS AMÉRICAS, 2012).

Outro aspecto sobremodo relevante é a vinculação do AIAG ao Acordo-Quadro sobre Meio Ambiente do MERCOSUL. Sendo partes integrantes do MERCOSUL, os estados componentes do AIAG reiteram e ratificam a importância dos princípios constantes no Acordo-Quadro de 2001, constantes do seu primeiro capítulo, a reverberar aqueles constantes das declarações internacionais, de seus objetivos, expressos no capítulo II (art. $4^{\circ}$ ) e a necessidade de cooperação internacional explicitada no capítulo III. Note-se, de modo especial, o texto do art. $3^{\circ}$, f, que dispõe: "fomento à internalização dos custos ambientais por meio do uso de instrumentos econômicos e regulatórios de gestão". A ideia é ratificada no art. 6o, i - "promover o uso de instrumentos econômicos de apoio à execução das políticas para o desenvolvimento sustentável e proteção do meio ambiente" - e figura, portanto, entre as ações prioritárias do Acordo-Quadro.

Trata-se da perspectiva oposta àquela do Tratado da Bacia do Prata, de 1969. Os danos ambientais decorrentes de uma economia de mercado liberal faz com que os países do MERCOSUL reproponham a questão socioambiental sob a ótica da precaução, prevenção e responsabilização pelos danos e custos da destruição ambiental, mediante instrumentos econômicos e regulatórios de gestão. A intervenção estatal é, do nosso ponto de vista, muitas vezes fundamental para equacionar a relação iníqua entre ganhos econômicos excessivos e esgotamento dos recursos naturais, especialmente notável nos países periféricos e em desenvolvimento.

Merece destaque ainda, no âmbito de nossa abordagem, por seu caráter diferenciado, o que dispõe o art. 6oㅡ, c, que propõem aos signatários: "buscar a harmonização das legislações ambientais, levando em consideração as diferentes realidades ambientais, sociais e econômicas dos países do MERCOSUL". 0 que deve ser complementado pela inteligência da alínea 'j' do mesmo artigo: "estimular a harmonização das diretrizes legais e institucionais com o objetivo de prevenir, controlar e mitigar os impactos nos Estados Partes, com especial atenção às áreas fronteiriças". Donde se conclui a importância singular da ciência do direito e da ação jurisdicional para a aplicação das diretrizes legais no sentido de prevenir, controlar e mitigar os impactos ao meio ambiente. E convém registrar a relevância que se dá, ao final do texto, às áreas fronteiriças, onde se podem incluir, sem uma hermenêutica demasiado larga, as águas fronteiriças, mesmo que superficiais e subterrâneas, como é o caso do Aquífero Guarani.

Nesse contexto de evolução dialética do direito internacional ambiental emerge o AIAG. Em decorrência, terá uma estrutura e propósito próprios, que gravitam em torno de aspecto bem delimitado e específico: o Aquífero Guarani, os estados titulares e a cooperação transfronteiriça. As declarações das conferências de meio ambiente da ONU e das cúpulas regionais seguramente tornam-se precedentes importantes. 0 avanço da concepção socioambiental há de se refletir no texto do Acordo. A referência explícita a esses conjuntos normativos internacionais, no início do Acordo, revela a importância daqueles princípios para sua precisa hermenêutica. 
Com efeito, no seu primeiro artigo, o AIAG, reconhece a titularidade das partes sobre o Aquífero Guarani. Ao mesmo tempo, são legitimadas ações cooperativas e/ou interativas. Boa parte do texto normativo se dedica justamente à equação e atribuição de obrigações relativas a cada parte no sentido de favorecer a proteção do todo. É o que se depreende especialmente desde o artigo 5o até o artigo 14 - em que se estabelecem os deveres e obrigações decorrentes de ações que interfiram no conjunto do Aquífero e afetem as águas dos estados fronteiriços, ao mesmo tempo, nos artigos 11 a 14, há referências explícitas à gestão compartilhada e o intercâmbio de informações técnicas e científicas sobre o Aquífero. A qualidade de aquífero transfronteiriço obriga as repúblicas pactuantes a esforços comuns para a sua tutela e proteção. No entanto, esse empenho compartilhado não elide a soberania nacional de cada Estado na gestão das águas dentro de seu território.

Para efeito desse artigo, vale lembrar a importância da gestão compartilhada. Os vínculos ecológicos no âmbito das bacias hidrográficas e do Aquífero impedem a ações necessariamente conectadas. A vulnerabilidade e sensibilidade dos corpos hídricos à contaminação fazem com que nenhuma ação seja isenta de interferência. A contaminação eventual das águas aparentemente tão distante das regiões fronteiriças - pode a médio e longo prazo repercutirem em toda a cadeia existencial dependente do Aquífero. E isso se faz, obviamente e com maior celeridade, nos âmbitos geográficos mais próximos e dependem das taxas de contaminação. Assim, a vigilância e o controle de todas as formas de efluentes, bem como a fiscalização das substâncias utilizadas nas diversas modalidades de atividades antrópicas, são fundamentais para a manutenção das águas em sua qualidade potável. Agrotóxicos, substâncias presentes na higiene humana e dos edifícios e toda a sorte de potenciais poluidores devem ser efetivamente fiscalizados e, em diversos casos, proibidos.

\section{Os embates em torno da apropriação simbólica e material das águas}

Também no âmbito da legislação ambiental nacional, o percurso histórico em matéria de direito das águas é uma trajetória significativa e com consideráveis avanços no sentido de estabelecer padrões relevantes de planejamento e gerenciamento. Todavia, como em quase todos os campos atinentes aos direitos sociais e difusos, a prática social, bem como a eficácia das normas, está aquém de sua proposta. Em justa medida, é possível até falar-se de conteúdos emancipatórios na legislação ambiental, quer nacional, quer estadual. Ou seja, a legislação deve servir de farol para ações concretas. No entanto, a complexidade dos embates sociais, das negociações em vista de consensos nas esferas administrativas e dos desafios de sua concretização, também no âmbito judiciário, fazem manifestar-se mais como lampejos que guias iluminadores de alta potência.

Para o campo de análise do direito das águas, cite-se, primeiramente, que 1934, houve basicamente um regime de águas no Brasil, que era a consideração dos rios navegáveis, e a sua utilização, era submetido ao direito das coisas (real), primeiramente por concessão régia, segundo as Ordenações do Reino e, depois, para o domínio nacional, com o Brasil Império e a República. No entanto, quer no Brasil Colônia quer no Império, e até 1934, vigia como marco regulatório o Alvará de 1804 do Reino de Portugal (POMPEU, 2009b, p. 47). O quadro alterou-se substancialmente com o advento do Dec. n. 24.643 de 10 de julho de 1934, chamado de "Código das Águas", que fora publicado no mesmo mês da publicação da Constituição de 1934, com a qual era compatível. Foi alterado em vista dos objetivos e disposições da Constituição de 1937, mantido por decreto-lei no conjunto do texto (BRASIL, 1934).

Elemento de grande relevo constante no Código das Águas é o fato de estar assegurado o uso gratuito de qualquer corrente ou nascente de água, para as necessidades vitais, se houver caminho que a torne acessível. Em não havendo acesso, os proprietários marginais não podem impedir que seus vizinhos delas se aproveitem para aquele fim, contanto que sejam indenizados do prejuízo que sofrerem com o 
trânsito pelos seus prédios. A servidão não é facultativa ou cessa quando houver meios de acesso à água de outra parte, sem grande incômodo ou dificuldade. Era ainda previsto no Código os sistemas de autorizações e concessões administrativa para as derivações de águas públicas. Num e noutro caso exigia-se a outorga do ente administrativo. A concessão havia para os casos de utilidade pública e os demais eram obtidos mediante autorização.

Atualmente, pela inteligência da Lei n. 9.966/2000, vige a autorização administrativa como regra, excetuando-se os casos de potenciais hidráulicos e são concedidas para os fins estritos e específicos, pelos respectivos titulares do domínio, hoje a União, os Estados e o Distrito Federal. Portanto, devido ao tempo de sua publicação, é mister relacionar o Decreto n. 24.643/34 com a legislação e regulamentações posteriores - especialmente com a Constituição Federal de 1988, e as leis infraconstitucionais de maior relevo, a saber: as Leis n. 9433/97 e 10881/04- sobre a Política Nacional de Recursos Hídricos, a Lei n. 9.966/2000 a respeito da poluição das águas nacionais; a Lei n. 9.984/2000 que dispõe sobre a Agência Nacional de Águas. Atenção especial merecem as alterações substanciais havidas pela Lei Federal $n$. 12651/12, chamado de o Novo Código Florestal, que inclusive revogou completamente a Lei n. 7754/89 que dispunha acerca das nascentes e mananciais de água doce. Neste caso especialmente, a legislação correlata é tão relevante quanto o Código das Águas e não pode ser menosprezada (BRASIL, 1989; 1997; $2000 ; 2004,2012$ ). Mas ao mesmo tempo, a legislação brasileira das águas apresenta-se como complexa e, por vezes, de difícil manejo e aplicação, o que reduz sensivelmente sua eficácia.

A Constituição Federal manteve o regime de domínio esboçado no Código, no entanto não conferiu aos Estados a competência legislativa complementar ou suplementar nesta matéria. Em matéria de competência legislativa e administrativa relativa ao regime das águas e no campo das outorgas administrativas, o que nos interessa especialmente, numa perspectiva sociojurídica, são as consequências das disposições atuais. Primeiramente, é muito salutar e conveniente que a competência legislativa das águas seja da União em razão de menor possibilidade de pressão dos grupos de interesse localizados. No Brasil, as administrações locais estão mais sujeitas aos jogos de interesses e tem menos força para impor os interesses públicos e barganhar que a União. Semelhantemente, parece que a titularidade de domínio, concentrada na União e Estados, supondo-se a custódia dos bens públicos, é de melhor adequação. No entanto, a ausência de competência legislativa complementar e suplementar parece contrassenso. Desde que limitadas à maior proteção do bem ambiental, há um ganho neste sentido. Evidentemente, uma competência legislativa in pejus é sempre refutável do nosso ponto de vista, nesta e noutra matéria ambiental. Todavia, deveriam ser favorecidas soluções locais que aprimoram o sistema legislativo e servem de modelo para o sistema nacional.

Supõe-se com razoável grau de acerto que há maior possibilidade de acontecer soluções locais aprimorantes, haja vista a proximidade com os efetivos problemas socioambientais das comunidades, e que isto deveria ser refletido nas instâncias maiores. Os organismos colegiados, como conselhos e comitês gestores ou consórcios e associações intermunicipais de bacias hidrográficas, por exemplo, tem condições de auferir danos e perdas, com sugestões de proposta de lei e interferir no processo legislativo local. E o controle constitucional e nacional se daria justamente pelo princípio do maior benefício ambiental. Em certa medida, é o que já ocorre não com as normas relativa aos domínios, titularidade. Mas já existem normas estaduais relativas ao uso, saneamento e outras medidas de controle ou impacto sobre as águas. Os Estados sobrejacentes ao Aquífero Guarani, por exemplo, possuem já normas relativas ao uso de suas águas subterrâneas (POMPEU, 2009b, p. 3).

Os Estados, embora tenham limitações legislativas no tocante à matéria dos corpos hídricos, tem possibilidade de fazê-lo, complementarmente ou subsidiariamente, no que concerne às políticas 
ambientais - ou seja, na forma de implementação da constituição e da legislação federal. Exemplo disso é a lei de recursos hídricos (Lei 7.663/91) do Estado de São Paulo, que expressa conteúdo programático de política ambiental. Com efeito, suas diretrizes e princípios introdutórios, são propostas de política pública no setor. Destacam-se os seguintes elementos da norma: - adoção da bacia hidrográfica como referência de planejamento e gerenciamento; - a administração descentralizada, participativa e integrada; - o reconhecimento do recurso hídrico como um bem público cuja utilização deve ser retribuída, a fim de assegurar padrões de qualidade satisfatórios para os usuários atuais e as gerações futuras; - a compatibilização dos usos da água com o desenvolvimento regional e a proteção do meio ambiente e a participação da sociedade civil nos colegiados de decisão. A lei possui proposta avançada e audaciosa, e intenta sistema de gestão com integração de programas e ações nas áreas de recursos hídricos, saneamento e meio ambiente. Portanto, configura-se nos moldes das atuais reivindicações socioambientais, em que o elemento antrópico é pensado em associação com a natureza.

A sua efetivação, todavia, implica outras ações sociopolíticas, sem as quais a norma se torna letra morta, a saber: 1) Plano estadual de recursos hídricos, elaborado a partir dos planos de bacia preparados pelos comitês e atualizado a cada quatro anos; 2) Fundo financeiro, que é Fundo Estadual de Recursos Hídricos (FEHIDRO), com recursos financeiros do tesouro do Estado, dos royalties do setor elétrico e da cobrança pelo uso da água; 3) Colegiados decisórios: integrados por representantes de órgãos e entidades do Estado, dos Municípios e da Sociedade Civil, com igual número por segmento. Há um colegiado central o Conselho Estadual de Recursos Hídricos (CRH), constituído por 11 representantes de cada segmento e os colegiados regionais; - os Comitês de Bacias Hidrográficas (CBHs), igualmente constituídos de forma tripartite, mas com número total de integrantes variável, segundo as características de cada bacia. A estratégia basilar dos Colegiados, por seu caráter eminentemente compósito, é a negociação e a busca de consenso, em que se estabelecem as prioridades de ações e investimentos e promovem a recuperação ambiental das bacias e o uso equilibrado dos recursos hídricos.

Convém assinalar que é justamente no nível local, especialmente no complexo regional e municipal, que sucedem as principais atividades de impacto e de gestão relativas à água. Donde se verifica a importância ímpar dos Planos Diretores Municipais e da implementação das ações constantes no Estatuto das Cidades relativas à proteção ambiental.

A Lei n. 9.433/97, que estabelece a Política Nacional de Recursos Hídricos (PNRH), manifesta objetivos dorsais de grande relevância no manejo e gerenciamento dos recursos, a saber: 1. a preservação da disponibilidade quantitativa e qualitativa de água, para as presentes e futuras gerações; 2. a sustentabilidade dos usos da água, admitidos somente os de cunho racional; e 3. a proteção das pessoas e do meio ambiente contra os eventos hidrológicos críticos. A Lei da PNRH, em seus artigos 1o, VI e 31, estabelece a competência dos municípios relativas à proteção do meio ambiente e fiscalização da exploração dos recursos hídricos, o que deve ser interpretado à luz dos preceitos constitucionais a fixarem a competência dos entes federados. Na Constituição Federal, a competência comum dos municípios decorre da inteligência do art. 23 VI e XI da Constituição Federal de 1988. Dentre os vários elementos relativos à gestão das águas no campo municipal, destaquem-se: 1. Serviços de água e esgoto satisfatórios, com tratamento adequado dos esgotos domésticos e industrias e redução dos vazamentos da rede de abastecimento de água são medidas eficazes e cuja relação custo-benefício é sem dúvida de grande monta em se tratando de gestão de águas. No caso do Aquífero Guarani, 70\% do uso de suas águas destina-se justamente ao abastecimento da população, razão por que merece atenção especial o serviço de abastecimento (POMPEU, 2009b: 12); 2. A contaminação das águas, especialmente as subterrâneas, em decorrência dos resíduos químicos e dos resíduos sólidos. 
Neste sentido, há problemas acentuados e persistentes no Brasil como o uso de pesticidas na lavoura, que tem se incrementado e a contaminação pelo despejo de dejetos em decorrência da ausência de saneamento adequado. Há notícias de que, na última década, o uso de pesticidas no país avançou $230 \% \mathrm{e}$ o Brasil já lidera o mercado mundial de consumo de agrotóxicos, que é comemorado pelos produtores e até pela coordenadoria de agrotóxico do Ministério da Agricultura, como se fosse uma vitória do setor agrícola como sinal da sua expansão, mas que implica em forte impacto nos lençóis freáticos, para onde se destinam com o escoamento das águas pluviais, além da contaminação dos alimentos, como constatado pela própria ANVISA (Agência Nacional de Vigilância Sanitária) - o que é ostensivamente negligenciado pelo setor agrícola e a industria fármaco-química associada que privilegiam os ganho estratosféricos, com um giro anual de mais de 7 bilhões de dólares!. E ainda pior: sequer há um aumento considerável da produção como era de se esperar! (PACHECO, 2009; GUILHERME et al, 2000; ANVISA, 2011; JORNAL DA CLUBE, 2011 a; 2011b). A transformação substancial das técnicas de manejo do solo, do incremento das formas intensivas de agricultura e da busca de uma agricultura de base ecológica é um imperativo. Há também os resíduos químicos oriundos da indústria - cada vez mais controlado, mas cuja punição e aplicação de penas aos transgressores não tem coibido ou desincentivado de maneira categórica. Os casos da indústria petrolífera no mar tem se tornado emblemático - mas há muitos mais no campo dos recursos de água doce onde o controle é ainda mais diluído. Com relação aos resíduos sólidos, a Lei n. 12305/10, que institui a Política Nacional de Resíduos Sólidos, condiciona a obtenção de recursos da união a elaboração dos Planos Municipais de Gestão Integrada de Resíduos Sólidos (cf. art. 18). Os lixões estão proibidos e os aterros precisam observar os padrões legais. A obrigação da logística reversa para os produtos especificados no art. 33, que tem alto poder contaminante, tais como agrotóxicos, pilhas e baterias, pneus, lâmpadas fluorescentes, de vapor de sódio, de mercúrio e de luz mista, óleos lubrificantes, produtos eletrônicos e seus componentes, devem contribuir com o controle da poluição ambiental e, por via direta, proteção das águas - haja vista que alguns destes produtos possuem componentes altamente contaminantes. Impõe-se a toda sociedade, a responsabilidade compartilhada (órgãos públicos e produtores) sobre a produção de resíduos (sobretudo os perigosos) e sobre os rejeitos (aqueles que não podem ser reaproveitados) (cf. art. 30, 37 e 47). Com relação à hidrologia, há uma vedação expressa na norma que os rejeitos ou resíduos sejam lançados em praias, mar ou quaisquer corpos hídricos (art. 47, I), mas a prática está longe de alcançar essa proposta legal; 3 .A aplicação das normas protetivas relativas à cobertura vegetal: os municípios devem atentar para que as áreas privilegiadas de cobertura vegetal, notadamente as APPs (Áreas de Preservação Permanente). Com efeito, são consideradas APPs aquelas de significativa importância ecológica, cobertas ou não por vegetação nativa, que têm como função preservar os recursos hídricos, a paisagem, a estabilidade geológica, a biodiversidade, o fluxo gênico de fauna e flora, proteger o solo e assegurar o bem estar das populações humanas. É o caso específico de áreas de mananciais, das encostas com mais de 45 graus de declividade, dos manguezais e das matas ciliares. Essas áreas estavam relacionadas e protegidas pela Lei Federal no 4.771/65,o Código Florestal, notadamente nos art. 1o. e 2o., alterado pela Lei Federal n. 7803/89, e recentemente objeto de reformas maiores (ANDRADE JÚNIOR; MANIGLIA, 2011).

Ainda que no bojo das modificações do novo código florestal houve a pretensão de inserir alterações nas modalidades de APP, especialmente sobre a extensão de matas ciliares a serem protegidas ou sobre a aplicação ou não em pequenas propriedades rurais ou nas encostas, substancialmente não houve mudanças no sentido de que a proteção dessas áreas é essencial. Ademais, as próprias alterações sugeridas gozavam de pouco apreço dos movimentos ambientalistas, em razão da importância ecológica das áreas em consideração. Recorde-se que o art. 4º da Lei n. 12651/12, com a redação alterada pela Lei n. 12727/12, prescreve a exigência das APP, entre outras situações, nas faixas marginais de quaisquer cursos d'água naturais, perenes ou intermitentes, excluídos os efêmero, no entorno das nacescentes e 
olhos d'água, veredas, no entorno de reservatórios artificias, decorrentes de barragens. Em todos esses casos a largura ou o raio de preservação decorre da previsão legal (CARVALHO, 2012; FLOR; MARCELLO, 2012).

No campo do nosso interesse, cabe então ressaltar que os municípios, além das APP, podem instituir APAs (Áreas de Preservação Ambientais) estratégicas, como os são os parques e estações ecológicas ou de proteção da biodiversidade. É um instrumento normativo que há mais de um século tem propiciado uma maior inserção dos entes públicos nas políticas de proteção ambiental. 0 mesmo se pode dizer dos incentivos, notadamente fiscais e de diminuição dos entraves burocráticos, para a criação de Reservas Privadas de Proteção à Natureza, que são bons instrumentos de política ambiental, criando parcerias importantes com a sociedade civil - o que se pode dar até na gestão das Unidades de Conservação de caráter público. Isto tudo, obviamente, em virtude da intrínseca relação entre cobertura vegetal e corpos hídricos, é de grande relevância para a proteção ambiental das águas.

Assim, os municípios podem e devem criar zoneamentos ambientais prioritários, com o reconhecimento de áreas especiais de conservação, maiormente naquelas respeitantes à biodiversidade endógena, aos mananciais dos rios, ao reflorestamento com espécies nativas, à proteção das águas subterrâneas e às políticas de monitoramento da produção agrícola (em especial no que concerne à produção de resíduos tóxicos). Os municípios que compreendem a área do Aquífero Guarani, dentre os que se destaca a região de Ribeirão Preto, que se entende como local de afloramento do aquífero, têm, neste sentido obrigação particular de defesa e proteção ambiental.

Dois elementos também emergem como muito salutares à tutela das águas, a saber: 1) Consórcios intermunicipais - haja vista que os corpos hídricos dizem respeito em não raras vezes a uma região geográfica superior aos limites municipais, é muito recomendável e desejável que se estabeleçam consórcios municipais, em vista da proteção ambiental, cujos nomes ainda são variáveis - Consórcio Intermunicipal de Bacias Hidrográficas, Consórcio Intermunicipal de Gestão Ambiental de Bacias Hidrográficas, Consórcio Intermunicipal de Macrorregião Ambiental. A exemplo do que ocorre com o EIBH (Estudo de Impacto sobre as Bacias Hidrográficas), cuja importância é muito marcante na gestão dos recursos hídricos, os consórcios municipais são de grande relevância no gerenciamento e proteção dos corpos hídricos. Muitas são as razões: 1 . uma vez que podem ser compostos de entidades privadas e governamentais tendem a ser representativos da sociedade e servem como elementos de controle da administração pública; 2. subsidiam a gestão pública na obtenção de elementos técnicos para a consecução dos Planos Municipais; 3. por serem colegiados, tem a vantagem de imprimir uma dinâmica democrática à gestão dos interesses públicos; 4. a União pode delegar-lhes as funções de Agências de Bacia. 2) Sistemas de drenagem: os municípios não possuem águas sob seu domínio, no entanto, cabelhes, não raras vezes, a drenagem dos solos em vista da urbanização ou até mesmo da organização rural (como no caso das estradas vicinais). Neste ponto, é importante o Estudo Prévio de Impacto Ambiental (EPIA ou EIA), como instrumento de gestão, haja vista que em não poucas vezes, as áreas de várzeas, outrora drenadas para a ampliação urbana, tornam-se polos de problemas hidrológicos de grande intensidade - como é o caso emblemático das enchentes da capital paulista. Ou seja, impõe-se aliar-se à natureza e não opor-se a elas - que nos projetos de urbanização os elementos georreferenciais sejam pontos fulcrais nos projetos urbanísticos e arquitetônicos.

\section{O Direito das Águas e as políticas nacionais e estaduais: expressão metajurídica e emancipatória?}

Embora esteja explicitada na CF/88 (art. 22, IV) a competência da União no tocante às águas, superficiais ou subterrâneas, os Estados, Distrito Federal e municípios podem estabelecer regras no âmbito 
administrativo. Exercem-na a título suplementar (art. 24, § 2o.), podendo até fazê-lo de forma plena para atender as peculiaridades das águas sob o seu território, quando inexistem disposições gerais federais pertinentes e até o advento destas. Haja vista que no tocante as águas subterrâneas, a legislação federal específica - a Lei da Política Nacional de Recursos Hídricos - é bastante genérica, alguns estados da federação, entre eles, o de São Paulo, possuem leis destinadas à tutela das águas subterrâneas. (VILLAR, 2008, p. 59).

No que respeita aos aquíferos transfronteiriços, como é o caso do Aquífero Guarani, a Lei Federal $\mathrm{n}$. 9.433/97, institui o Sistema Nacional de Gerenciamento de Recursos Hídricos - SINGREH, que cuida do gerenciamento compartilhado desses recursos no Brasil, buscando a integração do conjunto de órgãos e entidades que atuam na gestão nesse campo. A ideia é concatenar as ações regionais, estaduais e municipais, àquelas das agências ou entidades federais, tais como a Secretaria de Recursos Hídricos e Ambiente Urbano (SRHU), da Agência Nacional de Águas (ANA) e do Conselho Nacional de Recursos Hídricos (CNRH). Os estados têm estrutura congênere àquela da Federação, a se compor das secretarias estaduais e conselhos de recursos hídricos. Os Comitês de Bacias Hidrográficas e as Agências de Água constituem os pilares desse modelo integrativo e procuram desenvolver ações regionais e transfronteiriças para a preservação das águas.

No âmbito federal, merecem ainda destaque a Superintendência de Conservação de Água e Solo cujas atribuições, decorrentes da Lei 9433/97, são: "promover, estimular e implementar programas e ações de suporte ao uso sustentável de aquíferos que cruzem fronteiras estaduais ou nacionais, ou que estejam hidraulicamente interconectados a corpos hídricos de domínio da União", bem como estabelecer o "plano de conservação de Água Subterrânea". Há ainda a previsão de celebração de Convênios de Cooperação entre a Agência e os órgãos gestores estaduais, articulados pela Superintendência de Apoio à Gestão de Recursos Hídricos (SAG), para a implementação dos instrumentos da lei supramencionada e na formação técnica de agentes habilitados, mediante capacitação. Cabe ainda relevar o Programa de Águas Subterrâneas (PAS), sob regência da Secretaria de Recursos Hídricos e Ambiente Urbano do Ministério do Meio Ambiente que visa a ampliar os conhecimentos básicos hidrogeológicos, propiciar a implementação e o fortalecimento institucional e legal, além da formular as políticas para as águas subterrâneas compatíveis com a Política Nacional de Recursos Hídricos (BRASIL/ANA, 2012; VILLAR, 2008, p. 63-64).

Um dos problemas maiores concernentes às águas subterrâneas é que, historicamente (até o advento da Constituição de 1988) foram compreendidas em seu valor eminentemente econômico. 0 código de mineração de 1967, por exemplo, concebia as águas subterrâneas como substâncias minerais, sujeitas à prospecção, pesquisa e lavra. Por conseguinte, costumavam ser associadas ao domínio privado (ao contrário das águas superficiais, tomadas em geral como bens públicos - águas públicas). Esses elementos, assim dissociados, repercutiam na dualidade dos mecanismos estratégicos de tutela de ambas. A CF/88 alterou substancialmente esse entendimento, distinguindo as águas subterrâneas, de dominialidade dos Estados e Distrito Federal, dos recursos minerais do subsolo, cujo domínio é da União. A Lei da PNRH, de 1997, artigo 1ํ, ratificou a definição da água como de domínio público, sem distinguir as superficiais ou subterrâneas. Mas persistem, resistências a esse novo entendimento, que se refletem em políticas públicas fragmentadas. Todavia, a ANA tem justamente enfatizado a necessidade de se estabelecerem mecanismos integrativos, que representem a indissociabilidade da gestão dos recursos hídricos superficiais e subterrâneos. Esse entendimento é promovido especialmente pela Lei $\mathrm{n}$. 9984/2000, mediante a criação do SINGREH, e consta inclusive da Resolução n. 15, do Conselho Nacional de Recursos Hídricos (CNRH), de 11 de janeiro de 2001. Isso decorre por diversos fatores, e merecem destaque elementos de duas ordens: 1. das águas superficiais para os aquíferos (rios encaixados em 
fraturas alimentam os aquíferos) e 2. das águas subterrâneas aos aquíferos (as áreas de descarga ou exutório dos aquíferos alimentam os sistemas fluviais). (FREITAS, 2001, BRASIL/CNRH, 2001).

É fundamental perceber que a bacia hidrográfica passa a ser considerada a unidade de aplicação da Política de Recursos Hídrico, com o advento da LPNRH (L. 9433/97). As obras de captação de águas subterrâneas constituem-se como obras de engenharia e, portanto, requerem autorização para instalação e operação. Em decorrência, também no âmbito estadual, emerge clara a relevância dos Comitês de Bacias, como espécie de "parlamento das águas" para a governança e o estabelecimento integrativo das políticas macrorregionais. Com efeito, as normas federais e estaduais recebem concretude na integração regional no caso das águas subterrâneas transfronteiriças, como é o caso do Aquífero Guarani.

Tema que merece atenção especial, vinculado aos Comitês de Bacia, é a dessedentação e a cobrança na utilização na Bacia do Pardo. A ANA, em sua Política de Recurso, estimula a criação de comitês de bacia e agências de água, inclusive para a implantação da cobrança pela utilização dos recursos hídricos. A cobrança fora instituída pela L. n. 9433/97, na qualidade de instrumento de gestão da PNRH, e com os seguintes objetivos, segundo o art. 19: a) reconhecer o valor econômico da água e prover o usuário do valor real da água consumida; b) incentivar o uso racional da água; c) obter recursos financeiros para a recuperação das bacias hidrográficas do país. Tem caráter de remuneração estabelecida pelos Comitês de Bacias Hidrográfica (CBHs) - preço a ser fixado em pactos públicos entre os usuários, a sociedade civil e o poder público. Ao CBH compete a fixação do valor e a autuação e depende de aprovação pelo CNRH (Conselho Nacional de Recursos Hídricos). Para os fins de recuperação das águas das bacias, competirá à ANA repassar às agências de água das bacias ou entidade delegatárias os recursos financeiros para essa finalidade específica conforme a previsão da Lei Federal n. 10.881/04 associada à Lei 9984/00.

Todavia, o artigo 12, I, sujeita à outorga os recursos hídricos cujo uso é resultado da derivação ou captação de parcela da água existente em um corpo de água para consumo final, inclusive abastecimento público, ou insumo de processo produtivo. Associado ao art. 20 entende-se que esses usos são objeto de cobrança. 0 melhor entendimento, para mim, é de que se exclui a o usuário final para fins de dessedentação. 0 usuário final estará sujeito às taxas de utilização pelos serviços públicos prestados mesmo assim subordinados a condicionantes sociais. Como veremos adiante, os tribunais têm entendido que não cabe sequer corte de abastecimento de água mesmo em casos de débito com a concessionária. Nesses casos, não há relação propriamente de consumo e tampouco há aplicação do Código de Defesa do Consumidor. 0 que está sujeito à cobrança são os usos comerciais da água - o que se tem avançado significativamente no âmbito das tratativas internacionais e constituem-se prioridades estabelecidas nas normas federais. A dessedentação da população é direito humano fundamental, posto que associado ao direito à vida e à sobrevivência humana, razão porque é inconcebível a cobrança do consumo de águas nas condições existenciais. A cobrança deve destinar-se ao consumo para fins comerciais, agrícolas e industriais, com perspectiva eminentemente econômica e/ou mercadológica.

Ainda no âmbito da política estadual concernente à tutela das águas, há que se destacar seu pioneirismo no tocante às águas subterrâneas. Igualmente, esse pioneirismo precisa ser entendido na dinâmica da contínua e amadurecida reivindicação do movimento socioambiental. Portanto, não se tratam de concessões e benesses de um estado 'preocupado' com os direitos intergeneracionais. Ao contrário, reflete uma percepção da sociedade e um embate profundo das lideranças ambientais engajadas, que conseguem, a duras penas, impor padrões novos de governança. Com efeito, pela Lei n. 6134/88, instituiu-se diploma legal específico que 'dispõe sobre a preservação dos depósitos naturais de águas subterrâneas, e dá outras providências'. No caso federal, a política acerca das águas subterrâneas está compreendida no âmbito da Lei da PNRH (L. n. 9.433/97) e das Resoluções específicas do CONAMA e da 
CNRH, que acabam por impor uma interpretação uniforme da norma. Merece destaque, no âmbito das políticas federais, a Resolução do CONAMA, n. 396/2008, que dispõe sobre o enquadramento das águas subterrâneas, e a Resolução CNRH, n. 15, de 11 de janeiro de 2001, do CNRH, que estabelece as diretrizes gerais para a gestão de águas subterrâneas. Em seus artigos $2^{\circ}$ e $3^{\circ}$, dispõe sobre a necessidade de consideração da interdependência das águas superficiais, subterrâneas e meteóricas ${ }^{2}$ na formulação de diretrizes para a implementação da Política Nacional de Recursos Hídricos (BRASIL/CONAMA, 2008; BRASIL/CNRH, 2001).

0 artigo primeiro traz o conceito jurídico de águas subterrâneas, a saber: "as que correm natural e artificialmente no subsolo, de forma suscetível de extração e utilização pelo homem" (art. 1ํ, Lei n. 6134/88). Ademais, embora anteriores à Lei da PNRH, elas já compreendiam a necessidade de uma compreensão integral das conexões hidrológicas, para efeito tanto de aproveitamento quanto de preservação/conservação, conforme se depreende explicitamente do art. $2^{\circ} \stackrel{0}{0}$ que deve ser entendido conjuntamente com os artigos $4^{\circ}$ e 5ㅇ que estabelecem, respectivamente, a necessidade de programas permanentes de preservação e conservação mediante aproveitamento racional das águas subterrâneas, com a proibição expressa de descargas de poluentes com efeitos degradantes.

A lei estadual foi regulada pelo Decreto Estadual n. 32955/91. Em seu artigo 4ํ․ são previstas ações estratégicas específicas para o gerenciamento das águas subterrâneas. Elas repercutem o artigo 4o da Lei n. 6134/88. Associadas, permitem inferir quais as estratégias prioritárias, que tomamos a liberdade de expressar nos seguintes termos: I. avaliação, fiscalização e preservação dos recursos hídricos subterrâneos e planejamento de seu uso racional, com a consideração das cadeias físico-químicobiológicas; II. outorga e fiscalização de uso dessas águas e, III. Aplicação de medidas de conservação desses recursos, de combate à poluição e a superexploração. Também no art. 9o da Lei n. 6134, consta a previsão do estabelecimento de áreas proteção aos locais de extração, para a preservação e conservação dos recursos hídricos subterrâneos. Recorde-se ainda que entre a Lei e o Decreto, fora promulgada a Constituição Estadual Paulista, que recepciona elementos constantes na Lei n. 6134/88. Em seus artigos 205, I, há previsão de priorização do abastecimento populacional. No art. 206, são retomadas as ideias de combate à poluição e à superexploração, com a necessidade de implantação de programas permanentes de preservação e conservação. E, finalmente, a ideia do controle à erosão, com conservação do solo agrícola e urbano, como instrumento de proteção das águas subterrâneas e mesmo superficiais (art. 209).

Em nosso ponto de vista, a dessedentação e o equilíbrio natural das águas devem ser concebidos como princípios basilares do direito das águas, decorrente de direito humano fundamental, aos quais devem se subordinar toda a disciplina da água. Isso deflui do art. 206 da Constituição Estadual, onde se lê: "as águas subterrâneas, reservas estratégicas para o desenvolvimento econômico-social e valiosas para o suprimento de água às populações, deverão ter programa permanente de conservação e proteção contra poluição e super exploração, com diretrizes em lei”. O ideal é que a ordem fosse invertida, e que o suprimento às populações precedesse a ideia do desenvolvimento econômico-social. Aliás, nesse ponto também seria recomendável a inversão: a locução preferível seria desenvolvimento socioeconômico, reproduzindo assim a ordem já expressa no artigo 192 e mantendo a coerência redacional e semântica. A perspectiva econômica, enquanto dimensão relevante, não pode ser concebida como prioritária e tampouco como princípio fundante. Mas a leitura conjuminada com os artigos anteriores do capítulo,

\footnotetext{
${ }^{2}$ Interessante é a introdução na Resolução da categoria de águas meteóricas, que, segundo consta do art. $1^{\circ}$, II, são aquelas "encontradas na atmosfera em quaisquer de seus estados físicos". No mesmo artigo, em seus incisos I, III e IV, constam as definições respectivas, para efeito da lei, de águas subterrâneas, aquífero e corpo hídrico subterrâneo.
} 
especialmente o citado 192 e o 193, que introduz a noção de qualidade ambiental, permite equacionar as variáveis implicadas, inclusive a econômica.

O Decreto Estadual n. 32955/91 é já bastante feliz sobre esse particular, quando condiciona o controle territorial, os projetos de irrigação, a perfuração de poços e a expansão industrial à observância dos interesses de preservação e manutenção do equilíbrio natural das águas, aos quais se subordinam a captação, o uso racional e o controle da exploração hidrológica - conforme o disposto no conjunto da Lei, especificados nos artigos $5^{\circ}$ a $10^{\circ}$ do diploma legal. Destarte, uma boa hermenêutica permite inferir que a Constituição Estadual, na seção II do capítulo IV, intitulado "Do Meio Ambiente, dos Recursos Naturais e do Saneamento", retoma esse entendimento expresso anteriormente no decreto, os recepciona e os eleva ao nível de normas constitucionais do estado e, assim, com prevalência hierárquica às demais disposições gerais das normas infraconstitucionais. Isso está em pleno acordo com o princípio de que a lei ambiental precisa avançar sempre no sentido de maior e melhor tutela do patrimônio natural.

A ideia do combate à erosão, constante tanto do decreto estadual n. 32955 quanto constituição estadual, necessariamente implica numa concepção integral da natureza, assim como a referência explícita a ciclos hidrológicos e a manutenção das condições químico-físico-biológicas das águas. 0 mesmo se aplica à ideia de abastecimento da população. Ou seja, as políticas públicas de caráter socioambiental são munidas de potencial de sucesso quando incorporar sentido holonômico, na perspectiva que tratamos especialmente nos dois primeiros capítulos dessa tese. Importa inteligir as necessidades humanas numa perspectiva ampla, em que se conectam as dimensões antropossocial, biológica e ecológica.

Quero evidenciar aqui a vinculação da política das águas com aquela da produção energética. Dois pontos precisam ser considerados, a saber: 1 . 0 primeiro, eminentemente positivo: a perspectiva integral da política dos recursos hídricos, haja vista que o potencial hidroenérgico configura-se como uma das principais destinações das águas no cenário brasileiro de há algumas décadas. Portanto, os temas devem necessariamente ser compreendidos como vinculados; 2. 0 segundo, que tem caráter polêmico e negativo, e decorre do primeiro, é que a política energética brasileira infelizmente tem se apoiado demais no potencial hidráulico para a produção energética. Não se contemplam alternativas em termos gerais e de política socioambiental, e tampouco outras matrizes, como a eólica e a solar, tem merecido pouco incentivo tecnológico e científico de desenvolvimento. Associado a isso está o monopólio dos consórcios de produção hidroenergética por grupos, alguns deles associados ao comando de empresas de internacionais, o que é por si preocupante, haja vista tratar-se de recurso estratégico do patrimônio nacional (PONZILACQUA, 2007, p. 197-205; 2011).

Ainda na esfera do Estado de São Paulo, mediante o Decreto n. 45805, de 15 de maio de 2001, fora instituído o Programa de Uso Racional da Água Potável. Com efeito, o Decreto prescreve no seu artigo 1o: "Fica instituído, no âmbito dos órgãos da administração pública direta, das autarquias, das fundações instituídas ou mantidas pelo Poder Público e das empresas em cujo capital o Estado tenha participação majoritária, bem como das demais entidades por ele direta ou indiretamente controladas, o Programa Estadual de Uso Racional da Água Potável”. Para a observância do Programa há obrigatoriedade da criação de Conselho de Orientação do Programa Estadual de Uso Racional da Água Potável - CORA, em todos os órgãos e entidades previstos no artigo anterior. E, institui-se também, pela inteligência do art. 5ㅜ, a criação em todas as secretarias e autarquias a Comissão Interna de Uso Racional da Água Potável CIRA. Todavia, percebe-se que a implantação, cuja previsão legal se dava em 15 dias da publicação do decreto, não tem ainda alcançado os fins almejados, ao menos nas pontas das articulações institucionais, ou seja, ainda permanece a cogência da redução imediata do consumo de água potável em $20 \%$ nos órgãos e entidades abrangidos pelo Programa. Pode constar como estatística, mas a prática não se 
conforma aos números. Há desperdícios notáveis e a instalação de mecanismos de captação de água pluvial, por exemplo, de fontes alternativas para fins outros que não a dessedentação e higiene, cresce a ritmo muito pequeno. Há, por vezes, falta de monitoramento preciso das ações de terceiros vinculados aos órgãos e instituições estatais - como os serviços de limpeza, que são essenciais no controle do desperdício das águas. Ademais, na prática, é dependente das denúncias de usuários e cidadãos. No Brasil, faltam modelos racionais de controle de vazão eficazes que impeçam a superexploração dos mananciais. Os registros de vazamentos e outros dispêndios são constantes.

É significativo que duas Súmulas respeitantes à Água do Superior Tribunal de Justiça (STJ), possuam enunciados relativos ao direito tributário. A primeira delas está associada também aos prazos prescricionais, matéria processual, portanto: "A ação de repetição de indébito de tarifas de água e esgoto se sujeita ao prazo prescricional estabelecido no Código Civil" (Súmula STJ 412). A segunda diz respeito à aplicação do princípio da progressividade tributária: "É legítima a cobrança da tarifa de água fixada de acordo com as categorias de usuários e as faixas de consumo" (Súmula STJ 407) - porque os bens ambientais estão associados ao núcleo das atividades econômicas assumidas pelo Estado.

\section{Conclusão: o percurso legislativo e judiciário entre os embates do dizer e do fazer o direito}

Há sinais evidentes, todavia, de transformação paradigmática no âmbito dos direitos socioambientais relativos à governança das águas. A ação conjunta de uma série de atores sociais engajados tem convergido para a mudança da tônica ambiental e fomentam esperança. É preciso mais e com maior velocidade, haja vista que problemas ambientais da ordem dos que aqui são tratados, demandam soluções com tempos exíguos. A prolongada estiagem verificada em várias regiões brasileiras, que atingiu visivelmente o Estado de São Paulo - ainda que mitigadas pelas recorrentes chuvas do final de 2015 e início de 2016, põe em alerta o sistema de abastecimento público de água e a necessidade de urgente de programas de cuidado permanente com mananciais, olhos d'água, controle estrito da explotação das águas subterrâneas e dos sistemas de distribuição e vazão de água.

Não se pode esperar uma reversão automática e absoluta do quadro ambiental, inclusive no que tange ao despreparo dos agentes da esfera do poder público. Tampouco é de se crer que os interesses mercantis sejam submetidos a uma perspectiva socioambiental de maior adequação, mesmo porque é hercúleo desvencilhar os interesses privados e da política local das estratégias de cuidado da natureza. Assim, no âmbito legislativo e administrativo é forçosa uma ação conjunta dos movimentos, grupos e associações que privilegiam a agenda ambiental para perfilar novas políticas públicas que fomentem a preservação de fontes e mananciais e a cobertura vegetal que as protege. No âmbito do judiciário, melhor seria a criação de varas especializadas, circunscritas às causas relativas à matéria ambiental, a exemplo do que já tem ocorrido no âmbito do Ministério Público, porque favoreceriam ainda mais a orientação das decisões, a criação e consolidação jurisprudencial. No âmbito do Ministério Público e da Defensoria, é preciso uma formação dos seus membros que os capacite, como agentes públicos e políticos que são, a investir na nova concepção metaindividual do direito, conforme as práticas que foram autorizadas pela constituição em vigor, mas superando as 'miopias' tradicionais das ações pontuais dos sujeitos individuais para a compreensão dos sujeitos coletivos.

\section{Referências bibliográficas}

ANDRADE JUNIOR, José Roberto Porto de; MANIGLIA, Elisabete. A reforma do Código Florestal: as mentiras contadas e as verdades não ditas. In: MANIGLIA, Elisabete (Org.). Direito, políticas públicas e sustentabilidade: temas atuais. São Paulo: Cultura Acadêmica, 2011. p. 19-28. 
BRASIL. Agência Nacional das Águas (ANA). A Ana na Gestão das Águas. Conservação da Água e do Solo. Disponível

em: <http://www.ana.gov.br/gestaoRecHidricos/ConservacaoAguaSolo/default2.asp>. Acesso em: 15 jan. 2012.

BRASIL. Agência Nacional de Vigilância Sanitária (ANVISA). Programa de Análise de Resíduos de Agrotóxicos em Alimentos (Para) - Relatório de Atividades de 2010. Brasília: Gerência Geral de Toxicologia, 05 de dezembro de 2011.

BRASIL. Conselho Nacional de Meio Ambiente (CONAMA). Resolução CONAMA n. 001/86 e 09/87 Disciplinam o processo de licenciamento ambiental e dá outras providências. Disponível em: <http://www.mma.gov.br/port/conama/res/res87/res0987.html>. Acesso em: 10 de set. 2011.

Resolução CONAMA n. 396, de 3 de abril de 2008. Dispõe Publicada no DOU, n. 66, de 7 de abril de 2008, Seção 1, páginas 64-68.

BRASIL. Conselho Nacional de Recursos Hídricos (CNRH). Resolução CNRH n. 15, de 11 de janeiro de 2001, que estabelece diretrizes gerais para a gestão de águas subterrâneas. Disponível em: $<$ ttp://www.cnrh.gov.br/index.php?option=com_content\&view=article\&id=14>. Acesso em: 04 abr. 2011.

CARVALHO, Eduardo. "Decreto com vetos de Dilma à MP do Código Florestal é publicado". In: http://g1.globo.com/natureza/noticia/2012/10/decreto-com-vetos-de-dilma-mp-do-codigoflorestal-e-publicado.html, consultado em 18 de outubro de 2012.

CONFERÊNCIA DAS NAÇÕES UNIDAS SOBRE MEIO AMBIENTE E DESENVOLVIMENTO. 1992, Rio de Janeiro. Convenção sobre diversidade biológica. Brasília: Senado Federal/ Secretaria de Edições Técnicas, 1997.

Declaração do Rio sobre Meio Ambiente e Desenvolvimento. Rio de Janeiro, 1992. Disponível em: <www. onu.org.br>. Acesso em: 15 nov. 2012.

CONFERÊNCIA DAS NAÇÕES UNIDAS SOBRE MEIO AMBIENTE HUMANO. Declaração de Estocolmo sobre o ambiente humano. Estocolmo, 1972. In: Biblioteca Virtual de Direitos Humanos da USP. Disponível em: <www.direitoshumanos.usp.br>. Acesso em: 15 nov. 2012.

CÚPULA DAS AMÉRICAS SOBRE DESENVOLVIMENTO SUSTENTÁVEL. Declaração de Santa Cruz de la Sierra. Santa Cruz de la Sierra (Bolívia), 1996. Disponível em: <www.summit-americas.org>. Acesso em: 16 nov. 2012.

CÚPULA MUNDIAL SOBRE DESENVOLVIMENTO SUSTENTÁVEL. Declaração de Johanesburgo sobre Desenvolvimento Sustentável. Johanesburgo, 2002. Disponível em: <www.mma.gov.br>. Acesso em: 16 nov. 2012.

ESTADO DE SÃO PAULO. Ministério Público Estadual (MPE) - Subprocuradoria Geral da Justiça Jurídica. Ato normativo n. 682/2011-PGJ, de 15 de fevereiro de 2011. (Pt. № 17.988/2011). Disponível em:

<http://www.mp.sp.gov.br/portal/page/portal/cao_urbanismo_e_meio_ambiente/rede_gaema/A TO-PGJ-624-10\%20\%28Metas\%20Gaema\%202010\%29.doc>. Acesso em: 10 maio 2012.

FLOR, Ana; MARCELLO, Maria Carolina. "Dilma faz 12 vetos ao Código Florestal e editará MP”. In: http://noticias.terra.com.br/brasil/noticias/0,_0I5795649-EI306,00-

Dilma+faz+vetos+ao+Codigo+Florestal+e+editara+MP.html, consultado em 25 de maio de 2012. 
GUILHERME, Luiz Roberto Guimarães et al. Contaminação de microbacia hidrográfica pelo uso de pesticidas. 2000. Disponível em: <http://www.dcs.ufla.br>. Acesso em: 02 jan. 2012.

JORNAL DA CLUBE. Poluição Aquífero Guarani. Disponível em: <http://www.jornaldaclube.com.br/videos/1483/poluiÇÃo-aquÍfero>. Acesso em: 19 jul. 2011a.

Fiscalização nas bacias que abastecem Aquífero Guarani. Disponível em: <http://www.jornaldaclube.com.br/videos/1406/fiscalizaÇÃo-nas-bacias-que-abastecem-oaquífero-guarani>. Acesso em: 19 jul. 2011b.

MERCADO COMUM DO SUL (MERCOSUL). Acordo-Quadro sobre Meio Ambiente do MERCOSUL. Assunção (Paraguai), 22 jun. 2001. Disponível em: <www.mercosur.int>. Acesso em: 17 nov. 2012.

PACHECO, Paulo. O Brasil lidera uso mundial de agrotóxicos: o mercado girou US\$ 7,12 bilhões e, apesar do avanço, lua de mel entre indústria e produtores deve ser passageira. Estadão, São Paulo, 07 ago. 2009. Disponível em: <http://www.estadao.com.br/> Acesso em: 10 set. 2010.

POMPEU, Cid Tomanik. 0 direito de águas no Brasil. In: Revista dos Tribunais, vol. 889, p. 47, Nov / 2009, DTR $\backslash 2009 \backslash 654$

. Aquífero Guarani: aspectos legais e institucionais da gestão. In: Revista dos Tribunais Online, extraída em 20 de dezembro de 2012, 17, p. 3 relativo à Revista dos Tribunais | vol. 881 | p. 73 | Mar / 2009 | DTR \2009\210

PONZILACQUA, Marcio Henrique Pereira. Direito, Conflitos socioambientais, ONGs. Curitiba: Honoris Causa, 2011

ou PEREIRA, M. H. As ONGs como mediação político-jurídica nas questões socioambientais ante o processo emancipatório das comunidade. Brasília: UnB, 2007 (Tese de doutorado)

REPÚBLICA ARGENTINA, REPÚBLICA FEDERATIVA DO BRASIL, REPÚBLICA DO PARAGUAI, REPÚBLICA ORIENTAL DO PARAGUAI. Acordo sobre o Aquífero Guarani. San Juan (Argentina), 2010. Disponível em: <www.itamaraty.gov.br>. Acesso em: 10 nov. 2012.

VILLAR, Pilar Carolina. Gestão das Áreas de Recarga do Aquífero Guarani: o caso do município de Ribeirão Preto, São Paulo. 2008. Dissertação (Mestrado em Ciência Ambiental) - Ciência Ambiental, Universidade de São Paulo, São Paulo, 2008. Disponível em: <http://www.teses.usp.br/teses/disponiveis/90/90131/tde-26052010-100627/>. Acesso em: 12 jul. 2012.

VILLAR, Pilar Carolina. Governança dos riscos e aquíferos transfronteiriços. GEOUSP - Espaço e tempo, São Paulo, n. 31 especial, p. 93-107, 2012. 